\title{
1. Informal governance in the European Union: an introduction
}

\author{
Thomas Christiansen, Andreas Føllesdal and \\ Simona Piattoni
}

\section{INTRODUCTION}

The study of European integration tends to focus on formal aspects of the integration process: formal decision-making procedures, the role and functioning of institutions, the provisions contained in the treaties, the operation of regulatory regimes in the various policy areas. This is hardly surprising: what is distinctive about the integration process in Europe - what distinguishes integration in Europe from international cooperation in other parts of the world is the creation and growth of a unique institutional and legal framework structuring the relations between the participating states. ${ }^{1}$ An early and still important contribution to the understanding of the integration process has been the 'integration through law' school which regarded the development of a supranational legal order as the key factor in the explanation of the integration process (Cappelletti et al. 1986).

If the formalization of interstate relations is regarded as the essence of the integration process, it is hardly surprising that scholars should concentrate on the formal procedures and the institutionalized arenas for decision-making. However, as has become increasingly evident in the course of recent developments in the European Union, there is an important undercurrent to the formal integration process. This concerns the operation of informal networks which link policy-makers to client groups as well as actors across EU, national and sub-national institutions, and influence (or at least seek to influence) decision-making in the EU. This practice of informal governance is, of course, not a recent phenomenon, but a long-standing dimension of EU politics. This is a recognition that has been reflected by some approaches to European integration: in particular the literature on policy networks and the new institutionalism writing of the 1990s have picked up on the less formal aspects of the EU policy process. ${ }^{2}$ Nevertheless, informal governance has never been systematically studied and assessed: this is the void that this volume seeks to fill. ${ }^{3}$ 


\section{INSTITUTIONS AND NETWORKS IN THE EU POLICY PROCESS}

Informal governance may have been a long-lasting feature of the European integration process, but only recently has this had major repercussions for political debate in the European Union. In 2001, the European Commission published a White Paper on European Governance in which it made the case, inter alia, for a more structured relationship with civil society. The desire of the Commission to formalize its relations with interest groups and nongovernmental organizations (NGOs) was in part a response to the allegations of nepotism that had arisen in previous years and ultimately led to the fall of the Santer Commission in 1999. ${ }^{4}$ Before looking at these allegations, and the consequences they have had for informal governance in more detail, we need to look at the broader picture of the Commission's relations with interest groups, the role of networks in the EU policy process and the implications these features have had for European governance. The Commission's ability to relate directly to interest groups has always been an important feature of EU politics, in particular the Commission's close cooperation with business leaders and trade unions, but over time these direct relations have involved an ever-wider range of non-governmental organizations populating the Brussels scene. This direct relationship between the Commission and interest groups has had great benefits for either side. The European Commission, as a comparatively small public administration, required technical expertise on the many policy areas in which it was active, and which it could not find in-house and did not want to rely on from national governments. The creation of policy networks linking Commission officials with representatives of interest groups and NGOs also aided the Commission in gauging the likely reception of future EU policies 'on the ground' - an important knowledge in a system of decentralized implementation where much of the success of EU policies would depend on voluntary acceptance and compliance rather than enforcement. Finally, policy networks of this kind tended to put the Commission in a central position - like the hub of the wheel - in the EU policy process. Interest groups, in turn, gained direct, often preferential access to the centre of European policy-making and could feed important information, which could shape policy decisions. Interest groups, too, acquired greater legitimacy and were sometimes helped by Commission money to survive and institutionalize. In other words, the Commission's proactive engagement with policy networks in the many area in which it has been charged with initiating EU policies has served both itself and its clients well.

More recently, however, a certain sobriety has set in. Observers have pointed to the potentially self-defeating competition between rival interest groups to gain access to, and be heard by, the Commission official(s) in charge 
of their 'dossier'. Clearly, if everyone has equal access, the ultimate effort in representing a distinct interest may be wasted. At the receiving end, the Commission has found it increasingly difficult to manage the logistics of evergrowing numbers of lobbyists and in particular to reconcile the policy of open access with the principle of equal opportunity. As lobbying in Brussels has come of age, so the differences in resources of the various groups and organizations have become more evident. And, with the weakening of the Commission after the 'Santer affair', there has been a realization among interest groups that influential national governments as well as the European Parliament may well be more promising targets of the lobbying effort. Nevertheless, while the activity of policy networks centred on the European Commission may not any longer be seen as all-powerful in bypassing national governments in the design of EU policies, they still occupy a central place in the EU policy-making system.

Therefore, while the Commission, as the EU at large, continues to suffer from the lack of legitimacy that comes with the perception of distance between itself and the general public, it did actually achieve a high degree of closeness with those in the first line of dealing with EU policies on the ground. Whether, in terms of the wider issue of legitimacy, this closeness to interest groups has been a virtue or a vice is a matter of debate. On the one hand, one can argue that while the EU may not reach the individual citizen, it actually involves those most immediately affected by EU policies, or at least their representatives (or self-proclaimed ones), in the deliberation and design of policy initiatives. On the other hand, one may criticize the very closeness (or cosiness?) of the relationship between policy-makers and interest groups as a violation of the principles of representative democracy, such as 'one person one vote' and political equality. In terms of this critique, the precise nature of the relationship between Commission officials and interest groups then takes centre stage.

One key aspect of this relationship has been its informality. Unlike the formal democratic process, with its basis in highly regulated electoral and parliamentary arrangements, lobbying in the EU has been largely unregulated. During the 1980s there was an attempt by the European Commission to license, as it were, 'European Economic Interest Groups' (EEIG). The idea was that by registering the groups who required access to the Commission, equal status could be bestowed upon them, and thus a semblance of equality of opportunity be achieved. At the same time, this could be seen as an attempt by the European Commission to enlist interest groups for its own purposes, whether these be specific policy agendas or a more general search for legitimacy. While the EEIG scheme may in certain cases have contributed to the development of policy networks, it neither explained the growth and significance of policy networks in the EU in the late 1980s and 1990s, nor did it properly address the normative issues arising from the operation of such networks. 
More recently, the Commission launched a new campaign to organize its relationship with client groups. The White Paper on European Governance, published in 2001, sought to address wider issues of reforming decisionmaking procedures in the European Union, in particular with a view to addressing the issue of democratic accountability of European governance. Links between EU policy-makers and interest groups here became part of a wider agenda of structuring the access of 'civil society' to the decision-making centre in Brussels. The White Paper had a difficult gestation period and has not yet led to an immediate flow of specific proposals to implement the very general notions contained in it. Still, it constituted an important contribution to the wider debate about EU reform which has begun after the Nice European Council of December 2000. ${ }^{5}$

Beyond this well-known phenomenon of policy networks, there are other kinds of informal politics at work in the EU system. One of these is the presence of networks growing not around a particular policy, but based on a shared identity among its members and cutting across policy issues. In reality, the notion of policy networks and related concepts such as advocacy coalitions and epistemic communities (see below), already imply a departure from the notion of interest-based politics, and a recognition of the significance of social processes among participants in the policy process. But beyond politics revolving around particular interests or policies there is the presence of identities which unites some actors and distinguishes them from others.

It may appear counter-intuitive to look for identity politics at the heart of the EU - an institutional construct that is frequently seen to be committed to a pan-European ideal, or else is regarded as committed to a technocratic, economic rationale. Yet, European integration has done little to extinguish national identity, and nationality provides in fact a fertile base for informal networks in Brussels. Not all actors may feel compelled to cooperate within such nationality-based networks, but there is, at the very least, the potential that national identity will provide the foundation for networking and thus offer opportunities to policy-makers and interest groups to overcome institutional boundaries in their pursuit of a particular outcome. And beyond nationality there are other identities - regional, social, gender - which have the same potential and may be invoked by those seeking to conduct informal politics.

It would also be mistaken to think that informal governance takes place only at the point of contact between European institutions and European society. There are other areas of European governance which are regulated by informal agreements or in which informal procedures and codes of conduct explain decisions and behaviours better than formal procedures and norms. Inter-institutional relations - between the Commission, Council, Parliament, member states and even the Court of Justice - often involve informal agreements which arise at times to smooth and at times to bypass the formal procedures. ${ }^{6}$ 
Looking at the EU in the light of these observations is to recognize the propensity of the system to engender informal relations. The clash between, on the one hand, highly formalized routines for decision-making and, on the other hand, the need for continuous negotiation of policies in order to achieve successful outcomes, creates ample opportunity for networking and other forms of informal dealings. In many ways, informal governance can be seen as the glue that holds the cumbersome and contradictory system of EU governance together. However, such a view has to confront the frequent criticism that EU policy-making is in fact dominated by preferential - potentially clientelistic and nepotistic - arrangements linking EU and national officials to interest groups and other actors.

Take, for example, the informal relations that exist among official representatives of different member states or among the officials of national and EU bureaucracies. These relations are often crucial for the smooth functioning and efficiency of the Council and the Commission, because they allow for the convergence towards common views and positions and for the creation of common normative standards and codes of conduct. Yet they also work to lock in particular political visions and administrative practices, which may not be shared equally by all. For efficiency's sake, appointments may be made among a close circle of known friends whose loyalty and other professional capacities may be well known to the appointee, or consulting jobs may be given to well-tested companies whose services were revealed to be precious in the past. However, such selective choices may also end up ossifying the system and privileging the insiders vis-à-vis the outsiders. This goes to show that the issue of informal governance in the EU is normatively more difficult to assess than it appears to be at first sight.

The role of informal networks in the EU policy process is now high on the agenda of the European Union. Whether the public and political debate will actually lead to the far-reaching changes demanded by some - and promised by the Commission itself - remains to be seen. But it is also evident that this important issue now receives the attention it deserves. However, it would be misleading to present this development as deriving solely from the problems of, and proposed solutions offered by, the European Commission. The significance of informal networks in the EU policy process - the operation of informal governance in the EU - derives from structural conditions of the European integration process as well as from the agency of a wide range of actors.

\section{STUDYING INFORMAL GOVERNANCE IN THE EUROPEAN UNION}

The literature on governance proposes both positive and negative definitions 
that define governance for what it is and for what it is not (see Jachtenfuchs 1997, p. 2 for a positive and concise definition, and Rhodes 1997, pp. 3-25 for a negative and extensive one). We define governance as the production of authoritative decisions which are not produced by a single hierarchical structure, such as a democratically elected legislative assembly and government, but instead arise from the interaction of a plethora of public and private, collective and individual actors. It reflects the increasing incapacity of democratically elected legislative assemblies and governments to muster the information and to control the resources necessary for effective policy-making in contemporary societies.

Governance is predicated upon the functional interconnectedness of individual and collective, private and public actors who, in order to reach a desired policy goal, need to mobilize resources which they severally control only to a minor degree. Only through the cooperation of formally independent actors can a policy decision be identified and implemented: because these actors are independent, cooperation cannot be commanded by a hierarchically superordinated institution - what we called a democratically elected assembly and government - but must be somehow enticed. Governance works only if all those who have something to contribute to a given policy solution - be it property rights, crucial information or veto power - are brought into the decision-making process through the enticement represented by the attainment of a superior good (that is, a desired policy decision). Governance is informal when participation in the decision-making process is not yet or cannot be codified and publicly enforced. On the one hand, because the actors who may contribute crucial resources to the decision-making process are not known in advance (otherwise their participation could be simply commanded), informal governance operates through the creation of semi-official arenas to which all those who can potentially affect the policy decision, or might be potentially affected by it, have access - at least in principle. At the EU level, these arenas either emerge autonomously through the spontaneous coordination of relevant actors or are sponsored by the Commission through the 'open method of coordination' (OMC). These semiformal bodies open a space for inventiveness and vision, which individual policy entrepreneurs as well as well-established interest groups may seek to occupy for the purpose of arriving at efficient policy solutions, but sometimes also with the goal of foreclosing access to opposed interests. In fact, policy arenas are never completely open but rather tend to close around established circles, so that some potentially affected interests and some potentially crucial resources may be left out of the decision-making process. Then again, informal governance works through informal relations which take place outside both the official structures and the semi-official arenas, and which shape or condition their operation from without by filtering access, setting the agenda, packaging deals and threatening retaliation. 
This informal aspect of governance thus clearly creates both opportunities and problems with respect to participation. The steering obtained through peer review and spontaneous coordination will be effective only if all crucial stakeholders are included in the policy-making process. If some of them are left out - unintentionally or due to the pre-emptive action of some insiders - then governance will not produce effective policy solutions and will fail in its task. Normally, then, it is left to the formal institution, under whose jurisdiction the policy issue lies, to seek to involve all crucial interests. Governance, to a certain degree, must therefore still take place 'in the shadow of hierarchy'. Failure to do so creates problems of legitimacy, as well as efficiency: while the formal institution in charge of a policy area may lack the power and knowledge to command cooperation, it will still be held responsible for failing to bring it about.

It will be evident from what has been said above that the European Union is a fertile ground for the application of these concepts. Indeed, it is surprising, given not only the recent debates in EU politics about the relationship between institutions and interest groups (and other clients), but also the longstanding propensity of the European Union to generate informal governance, that there has not been more research in this feature of European integration.

This volume provides a systematic examination of the informal aspects of EU governance which are either in the margins of traditional analyses or ignored altogether. Building on the insights developed above, we consider informal governance as the operation of networks of individual and collective, public and private actors pursuing common goals - which lead to cooperation, patterned relations and public decisions - through regular though non-codified and not publicly sanctioned exchanges in the institutional context of the European Union. While this definition establishes a specific category for the study of political action in the European Union, it still leaves numerous variables to be determined in subsequent empirical analysis. Two aspects, however, are necessary to the definition of informal governance. First, the exchanges are non-codified: there are no formal or written rules regulating the behaviour of political agents participating in informal governance, either because such behaviour is illegitimate or because the rules are in the process of being formulated through current practice. Second, the exchanges are not publicly sanctioned: while no public authority can have sanctioning power over such exchanges, they may be privately sanctioned through peer pressure, reputation or retaliation.

Informal governance raises analytical as well as normative questions. Most of them will be settled case by case through empirical analysis - whether the relations thus established are private or public, overt or covert, short or long term, stable or fluid, dynamic or static, single or multi level, based on an individualist or a collectivist ethos, rationality or value oriented, assist integration 
or favour fragmentation, engender convergence or divergence, seek to exert general influence or pursue specific policy outcomes - but we can preliminarily draw insights from the existing literature regarding at least three questions. First, which features of the European Union make informal governance paramount if not unavoidable? Second, which analytical constructs help us gauge the political participation afforded through informal governance? Third, are there cognate concepts in political science that could help us in the analytical and normative exploration of informal governance?

\section{INFORMAL GOVERNANCE AND EUROPEAN INTEGRATION}

The first question to be addressed here concerns the features of the European Union which make the presence of informal governance so prominent. The simplest answer is that the same reasons which explain governance in general apply with greater force to the European Union for the obvious reason that the EU has a non-hierarchical institutional framework. The EU has created potentially powerful institutions and their operation may be highly formalized, but there is no clear hierarchy between them, and only incomplete hierarchies within the institutions. Moreover, the EU lacks direct enforcing capacities. In the EU there is little of the hierarchical chain of command known from domestic political systems: claims that the EU is largely run from the unfettered centre are impossible to sustain in the face of the concurrence that is required from member states to put any policy into effect. At the same time, neither individual member states nor the collectivity of member states are in control of the integration process, given the role played by the Commission, Parliament and Court of Justice. And at the European level, political power is balanced between the Commission, Council and Parliament, and continuous cooperation among these institutions is required for any important decisions to be taken. ${ }^{7}$

The same is the case with respect to the internal politics of the European institutions. Thus, the Commission has a formal structure with a President at its head, and with 19 Commissioners in charge of a similar number of Directorate-Generals. However, Commission decisions are taken by the college of Commissioners collectively, and much of the work of Commissioner's personal staff, their cabinets, is concerned with the monitoring of the work done by other Commissioners. For the Commission to participate in the policy process as a single actor requires an immense effort to agree and coordinate policies internally in order to achieve cohesion. The upshot of that situation is that there is never a single department or individual in charge of any policy, but that responsibility for policy initiative is shared across the 
Commission. Similar conditions prevail in the Council of Ministers and in the European Parliament.

In addition to the coordination within the Commission, the cooperation across the EU institutions and the inter-level bargaining between national governments and EU actors in the making of EU policy, there is further consultation and cooperation at both national and European level with private actors. As discussed above, the Commission, in particular, likes to involve interests groups and NGOs in the policy process, partly because the involvement, if not the support, of European-level interests provides greater legitimacy for an emerging EU policy in any given area, and partly because the Commission's in-house expertise is limited and information provided by private actors helps the Commission to offset the informational advantage of national officials.

What results from the particular nature of governance in the EU is a nonhierarchical negotiation system: decisions require extensive consultation involving private and public actors even before draft proposals are tabled, and yet more discussions across the policy-making organs of the Union, and between Europe-level actors and member state representatives in the actual decision-making process. And also the implementation of policies within domestic systems is negotiated, involving actors not just at the national level, but also at the regional and local level as well as participation (or at least compliance) from the private sector.

This is not to say that EU policies are always agreed consensually among all participants - indeed, there are frequent cases when decisions have been taken against the vocal opposition of certain groups, segments of society or some member state governments. And decision rules obviously differ across policy areas and across the pillar structure of the European Union. However, in the absence of hierarchical structures, the EU system has a propensity towards the negotiation of outcomes in contrast to the partisan decisionmaking which is familiar from majoritarian systems on the national level.

Such a system - formally highly institutionalized but at the same time requiring continuous negotiation among the actors involved - has to contain a basic tension: policy-making has to both follow the formal decision-making rules (and thus obey institutional boundaries) while at the same time overcome institutional divisions in order to negotiate outcomes. This state of affairs applies to the internal politics of the Commission, to the relations between EU institutions and to the relations between national and European-level actors in each of these arenas of contestation the presence of formal rules and institutional fault-lines has been competing with the need for actors to negotiate and cooperate.

The resort to informal governance has been one important way in which the EU system has sought to resolve this tension. Policy networks, as discussed 
above, have been established among those involved in the making of particular policies, cutting across institutional affiliations and positions on different levels of policy-making. The presence of networks can help to narrow substantive disagreements among institutional or national positions, exert influence on decision-makers to agree on compromise solutions, and facilitate the acceptance of emerging policies in a variety of different domains. In this way, policy networks prepare the ground on which formal institutional mechanisms operate in the decision-making process. And much of the work of policy networks is informal, in that the contacts among actors are fluid, responsive to the requirements of the situation rather than following formal procedures.

\section{MEASURING PARTICIPATION IN THE POLICY-MAKING PROCESS}

The theories of pluralism and neo-corporatism have provided classical answers to the second question. On the one hand, the problem of the uneven representation of affected interests has long been identified in the policy studies literature as a critique of pluralism (Connolly 1969, Domhoff 1967, Edelman 1964, McConnell 1966, O’Connor 1973, Piven and Cloward 1971, Verba and Nye 1972, Wilson 1968 and 1980). While some interests are all too well entrenched in the policy-making process - embodying some variant of 'agency capture' or 'iron triangle' (Lowi 1979) - others are left to grapple with the difficulty of getting organized for action and breaking into the inner circle of the policy-makers (Bachrach and Baratz 1970, Lipksy 1970). On the other hand, neo-corporatism has clearly acknowledged the selectivity of policymaking circles (Offe 1981, Schmitter and Lehmbruch 1979, Schmitter 1981) but has elevated it to a greater good (Katzenstein 1985). Because the interests which participate in the decision-making process are visible, all-encompassing, and internally democratic, there is no danger of under-representation or undemocratic representation. It is the state, and ultimately the political system, which guarantees that the decisions thus made reflect as closely as possible the general interest of society.

More recently, the policy studies literature has sought to address the analytical shortcomings of both pluralism and neo-corporatism by elaborating the concept of the policy network that could account both for the staying power of given interest groups and for the less than systematic pattern of interest intermediation at work in most European political systems. The policy networks literature thus occupies that analytical middle ground between pluralism and neo-corporatism that is best described in terms of 'neither . . . nor'.

The relations that develop around policy decisions are neither haphazard, as pluralism would have them, nor are they sanctioned by state authority, as in 
neo-corporatism: they are not commanded, yet they are regular. The groups that cluster around policy decisions are neither constantly changing nor are they always the same: they vary from policy area to policy area. The pattern of interest intermediation neither corresponds to a pluralist ideal type, in which every group has the same chance of accessing the government and promoting a policy decision, nor does it look like a (neo)-corporatist one in which only a small number of state-appointed or society-backed overarching groups can shape policy decisions. Government decisions are therefore neither the simple resultant of raw societal demands, as expressed by the occasional coming together of like-minded individuals, nor are they the expression of the codified, long-term interests of large social formations. The patterns typically described by the policy network literature both disperse and concentrate decision-making power in clusters of individuals and groups which, while being an expression of society, find in state relations a way to 'own' such expressive function and thus become a fixture of the decision-making machinery.

How are networks constituted? Which problems of participation do they solve and which do they leave unresolved or create anew? Networks operate at the level of relations among individuals, groups and institutions. Their constituent force is not simply people's like-mindedness or their common socio-economic background or some other categorical trait, but is rather functional complementarity, cultural affinity, and sometimes the purposeful action of some governmental agency in need of popular legitimation. Such networks often form among activists and functionaries which share given views and values and who use trust relations developed elsewhere towards formal decision-making. Thus while, also according to this approach, individuals and groups tend to become parts of the governmental machinery in much the same way that the critics of pluralism describe, they do so more through the kinds of mechanisms that explain everyday relations than for their institutional or societal power. In some ways, the policy network literature records an 'intrusion' of private life mechanisms into the public sphere, which can either don the benign smile of personal support groups or wear the malign grin of collusion and corruption.

Networks come into being mostly through personal relations - activating common interests, shared views and mutual recognition - and generate valuable resources such as knowledge, solutions and visions. The mechanisms through which such convergence is thought to occur is appealing: social relations support discursive argumentation and self-critical analysis based on the force of ideas and the power of empirical evidence. The large social formations in which issues are debated, knowledge generated, and solutions aired for the first time are called 'epistemic communities' (Haas 1992). The literature then labels 'advocacy coalitions' (Sabatier 1998) those more or less temporary line-ups of diverse actors who, sharing a common view of the 
policy issue, put pressure on governmental agencies for adoption of their preferred solution. The literature further distinguishes between issue networks, policy networks and policy communities, mostly on the basis of their openness and stability (Marsh and Rhodes 1992). To varying degrees, these intermediate formations display the traits of 'village communities': through the web of interpersonal relations meaning is shared, trust is developed, norms are established, opportunism is punished. From these relations good citizens may develop. Yet the danger is also present that in-group dynamics exclude outgroup members, views become parochial results of group think, and dissenters are ostracized. Through the process of accreditation into the policy community, the appreciative system of in-group members selects which ideas are aired, which voices are heard, and which information is considered valuable.

Less than noble exchanges may also be based upon such gate-keeping mechanisms: access to the decision-making network may be exchanged for conformity with current practices, thus injecting a measure of rigidity into the decision-making process. Worse still, access to closed decision-making networks could be exchanged for concealment of policy-sensitive information, and accreditation to a selected circle of implementing organizations could be exchanged for more than cavalier neglect for procedural correctness. These phenomena then border on practices, the best-known of which is clientelism, which have been unconditionally denounced as inefficient and illegitimate. Suboptimal decisions and goal deflection are, at a minimum, the consequences of such practices, but fraud and corruption could be the more likely outcomes.

\section{THE LEGITIMACY OF INFORMAL GOVERNANCE IN THE EU}

Governance is evidently a tricky concept. As soon as we leave the analytically and normatively firmer terrain on which the competing principles of hierarchy and market stand, we discover that we lack obvious normative standards for assessing governance. A number of critical empirical questions are immediately raised. How important is this form of decision-making: does it arise for single decisions, policies or when deciding on institutions and 'standard operating procedures'? Insofar as stakes are high for affected parties, the crucial issue of normative legitimacy seems inescapable: with what moral right can authorities expect subjects to comply? The capacity of bodies of governance largely depends on whether the subjects recognize them as legitimate in this sense. Individuals and organizations are often influenced by considerations of whether a command or arrangement is legitimate or fair, and whether such judgements are widely shared. Such perceived legitimacy is especially important to sustain mutual expectations of future willing compliance. Thus stable 
compliance with commands is largely a question of whether parties generally believe that all have reasons to comply. One objective reason for complying is that the authorities actually deliver results that you endorse. One requirement of such 'output legitimacy' is that the objectives are actually achieved. The EU is often criticized for being inefficient in this regard, due to multiple veto players, and partial compliance owing to weak enforcement mechanisms. Informal governance might cut the implementation costs and ensure compliance through social pressure and by binding the participants. However, it is not clear how informal governance can be entrusted to do so: there would have to be mechanisms of transparency, accountability and authority to ensure that informal governance remains effective in the long term.

A second subjective requirement of 'output legitimacy' is that the goals are ones you endorse or at least that they are arrived at through processes you accept. Thus the objectives of European integration were uncontroversial in the post-Second World War period, when integration secured peace through common command over goods necessary for war. Similarly, compliance is plausible to obtain Pareto improvements where some are made better off without making anyone else worse off.

The determination and the attainment of goals is more problematic when there are distributive conflicts, for instance when the gains of cooperation may be distributed in several ways, or when some parties insist on redistributive transfers. In such cases it may have to suffice that the procedures are acceptable, such as majority rule among affected individuals with equal influence on the basis of public deliberation. Such 'input legitimacy' would involve procedures that are responsive to all affected parties, and that settle contested issues by a defensible process of conflict management. Informal governance may be crucial for finding creative Pareto improving solutions, but it is not obvious that informal arrangements are well suited for contested distributive decisions, particularly if some of the claimants are not included. Moreover, informal processes lack standard mechanisms of ensuring reliability over time, since accountability is absent. There is no electorate that can 'kick rascals out' on the basis of scrutiny and competition among candidates with opposing political programmes.

Thus, informal governance has something to recommend it regarding creativity and finding effective means for obtaining results, and it may secure sufficient responsiveness when identifying the objectives to be achieved, but it has been found wanting when securing representation of all potentially affected interests.

In sum, informal governance must strike a balance between transparency and opaqueness, democracy and aristocracy, inclusiveness and selectiveness. However, it fails to spell out how a balance is drawn, how it is reached, and why it should be respected by citizens as legitimate and authoritative. Because 
of its practically expeditious, yet normatively dubious nature, governance has more than family resemblance with several political phenomena of long standing in Europe: pluralism and neo-corporatism as mentioned above, and clientelism - addressed below

Drawing in part on normative analysis of pluralism, neo-corporatism and clientelism, we can identify several issues that are problematic with regards to the legitimacy of informal governance:

- Authority: Who has the authority to invite participants, set the agenda, and implement the conclusions? Networks enjoy influence regarding input and output without due authorization, that is, without elections or explicit authority by the host institution to invite certain parties to a network with a particular agenda. Why should citizens be prepared to carry a cost imposed by someone whose only answer is 'because we say so', whose authority is invisible, unconstrained or otherwise unacceptable?

- Participation: Who participates, on what terms? Sometimes some of those affected must be excluded to obtain unanimity. Such strategies may of course cause a backlash if not all those with blocking power are included. Excluding some affected parties is especially problematic if they are also vulnerable and powerless, regardless of their threat potential. Apart, then, from being only dimly 'democratic', governance may not necessarily be effective either: we simply cannot be sure that all relevant or competent voices are heard before a decision is made. On the other hand, it is not obvious that all organizations have a claim to be included. For instance, there is no reason to assume that all participants in civil society are civil. Should governance require that the collective actors, which take part in the decision-making process, are internally democratically structured? Does this not carry the danger that, for want of democracy in the public decision-making process, we may feel tempted to 'democratize' (hence, tinker with) the internal structure of civil society groups? There is also reason to be wary of partial participation: collusion among those invited around the table may harm other parties. Skewed resources among the participants will likely affect the outcomes in problematic ways.

- Assurance: How do we ensure that justice is reliably done, and seen to be so done? The mechanisms of governance must economize on trust, in the sense that there should be ways for citizens to determine that objectives are fairly agreed to, and reliably pursued. Likewise, if these modes of decision-making are to maintain trust, there may have to be arrangements to ensure that they remain responsive to citizens' concerns over time. This points to a dilemma: how open should governance be to gather sufficient information for effective policy-making? How encompassing 
should it be to guarantee participation on equal terms for all? Should governance be procedurally transparent, so as to give everyone a chance to participate or at least to challenge the rules that guide it, or should it be opaque, so as to allow the attainment of balanced policy deals which could not be reached if they were thoroughly monitored and publicized? Should governance require that all decision-making be thoroughly publicized, so that interested or affected individuals and public pressure groups can monitor it and intervene in it to stop potentially harmful decisions? Would not this imply a fantastic diffusion of veto power that would surely block all policy decision-making?

These questions point to the difficulty of reaching decisions through governance which are both effective and democratic. Problems arise because it cannot be guaranteed that a system of governance represents all affected parties. In this respect, there are similar normative concerns as those that have been voiced with respect to pluralism: we know from critiques of pluralist theory that the intensity of a group's concerns are not proportional to the weight this group exerts on the decision-making process. In between lie a host of factors: from the difficulty of establishing collective action to the problem of groups' uneven access to organizational resources, from the relative concentration of costs and benefits to the existence of privileged relations between some groups or individuals and regulatory agencies.

\section{INFORMAL GOVERNANCE AND CLIENTELISM}

Finally, we need to provide an answer to the third question, whether informal governance can be likened to social sciences concepts with longer seniority. To do so, we will explore a concept which is often invoked to signal the double-faced nature of informal governance - practically expedient but normatively suspect - the concept of clientelism.

Clientelism is conventionally understood as an informal contractual relation between actors of different status and power who agree to exchange bundles of goods and services over a prolonged period of time without ever expecting to balance their accounts (see Silverman 1977 for a concise definition and Eisenstadt and Roniger 1984, pp. 48-9 for a more detailed one). Born in Roman times (Roniger 1983), clientelism has been mostly used to characterize the exchange relations between peasants and landlords in traditional agrarian societies, whereby the peasants would try to redress their unfavourable conditions by currying the favour of the landlords through a variety of services ranging from labour to reverence. In exchange, the landlords would ease the exploitative pressure off the peasants and lend a helping 
hand in times of trouble. This phenomenon reached its apex during the transition from feudal arrangements (in which peasant exploitation was mitigated by traditional norms of reciprocity) to the establishment of a free market for land and labour (which, at least in theory, gave the peasants the possibility of contracting on a par with the landlords) in that interregnum in which the peasants were effectively re-enslaved by the market. Because the peasants could not exit the 'deal' and obviously preferred to voice their discontent and bargain special conditions with their landlords on an individual basis, the situation remained exploitative, and clientelism is consequently seen as a way of inhibiting the collective action of the economically disempowered.

In more recent times, clientelism has acquired a pre-eminently political connotation without however losing its stigma as exploitation in disguise. ${ }^{8}$ Some of the original characteristic traits have remained - long-term exchange relationship between persons of unequal status and power - but others have obviously changed: the goods and services exchanged, the existence of more legal, although probably more onerous alternatives, and so on. Contemporary political clientelism is, by now, a freely entered deal which brings costs and benefits to each party (Piattoni 2001, p. 2), although not in perfectly equal proportions: paying for the consequences of such an agreement is a third party, normally the state - whose public resources are happily plundered by patrons and clients - and more generally all those who are excluded from such exchanges. Preferential relations are thus established and maintained, which repeatedly thwart competition and distort public decision-making.

In this updated and attenuated meaning, the term 'clientelism' has gained growing popularity. It is currently used to denote all long-term, mutually convenient (although not fully legitimate) deals which restrict competition within closed circles. These deals are not fully legitimate precisely because they tend to limit the selection of the partners to pre-established groups of 'friends' who may have a common interest in exploiting some available pool of public resources and keep the outsiders out. But they may also be simply explained by the conveniency of not having to continuously renegotiate the terms of long-term relationships based on mutual knowledge and trust (cf. Verdier 1995). In other words, clientelism is premised on very similar assumptions as those which sustain the networks through which informal governance typically works.

To denote some of the informal relations which surround European decision-making as 'clientelistic', hence draws attention to two potential dangers. On the one side, the danger that informality - lack of enforceable and sanctionable procedures - may tend to generate corruption and nepotism. On the other, the danger that, in order to achieve results and boost their power, European institutions may indeed undermine their credibility and legitimacy.

These questions, as well as the others outlined above, will receive varying 
answers from the individual studies. How stable are such informal networks, and how does the degree of stability of informal networks impact on their operation? On what basis, or around which common goals or shared visions, do such networks form? To what extent does informal governance offset the formal decision-making procedures of the Union? Are there instances in which informal governance in fact serves to inject greater efficiency into the formal arrangements of policy-making in the EU? There are, however, also the normative questions raised above to keep in mind when reviewing the evidence on the scope of informal governance in the EU. Are informal networks sufficiently responsive to affected parties, and sufficiently accountable to remain legitimate over time? Does the presence of informal networks affect the outcome of decision-making processes? And, last but not least, how do we normatively approach the issue of informal governance?

\section{ORGANIZATION OF THE BOOK}

The contributors to this volume seek to address these questions from a number of different angles. Some of the contributions address the foundations or driving forces of informal governance in the European Union, while others analyse the operation of specific networks in the context of particular EU policies. Among the former, Ulf Hedetoft offers a chapter examining the way in which the European Union has developed a distinct political culture related to but nevertheless distinct from the political cultures of the member states of the Union. Based on this exploration of the EU's political culture we can ask whether informal governance is inherent in such a cultural environment, or whether institutional changes can accommodate different perspectives on policy-making.

Alison Woodward, in her contribution, explores the relevance of identity in the formation of informal networks. Her case study centres around the mainstreaming of gender equality policies, and the way in which these policies have been driven by an informal network involving Commission officials, member state representatives and activists in NGOs. It demonstrates that a shared identity - in this case a gender identity - facilitates the creation of effective informal networks.

In her contribution, Carolyn Warner introduces the concern about the 'material benefits' of participating in informal networks. She examines the incidence of fraud in the EU and discusses the particular reasons for fraud being such a prevalent issue in the Union. Clearly fraud, and the way it has grown since the launch of the Single Market in the 1980s, throws a shadow over the role informal networks play in this respect.

This leads to a discussion of the normative assessment to be made of informal 
networks. Informal governance, on top of the slippery slope leading from clientelism to nepotism and fraud, is generally regarded as normatively dubious and hence illegitimate in the context of EU politics.

The chapter by Alex Warleigh explores precisely the efficiency-legitimacy dilemma of informal governance showing how the very aspects which increase the former end up detracting from the latter. It takes two rather distinct 'actors' involved in informal governance: NGOs and the European Parliament (so, civil society groups and a formal European institution). It contributes to the volume by taking a different vantage point from which to observe informal governance (that of actors rather than policy areas) and by widening the range of actors involved (indeed, by studying relations between institutions, rather than between individuals). In either case, the conclusions are rather pessimistic: informal governance in the EU tends to widen the range of elite-level actors who are influential players in policy networks rather than the constituencies that they are supposed to represent. Both NGOs (which aim first and foremost at their perpetuation and do not disseminate information or educate their members) and the European Parliament (more concerned about coming to terms with different EU institutions than with representing their constituencies) do not really enhance the representational capacity of EU policy-making.

A number of authors then provide studies of specific policy areas and the operation of informal networks within them, addressing the questions about informal politics raised above.

Raj Chari and Hilary McMahon look at the field of competition policy, in particular the Commission's activity with respect to merger and antitrust decisions, and raise the question as to whether the formal rules in this area of decision-making are compromised by the influence exerted by interested parties, including national governments, through informal channels.

Jenny Fairbrass and Andrew Jordan look at the way in which the rushed acceptance of EU biodiversity regulation by the British government, on the basis of the perceived greater stringency of the standards already in place at home, gave the opportunity to extremist environmentalist groups to push regulation still further. While it exposes the miscalculations of British authorities, it also reveals the open-ended nature of European policy-making and the space that exists for political entrepreneurship through informal policy networks. It emphasizes how informal governance develops around formal governance processes because of the well-known limitations in knowledge, expertise and staff of the Commission. From the chapter we gain the impression that timely mobilization and perhaps also a particular nationality slant (the British and northern Europeans won over the French and Southern Europeans) favoured one network (the pro-biodiversity network) over another (the pro-hunting network). 
In his chapter on the European Electricity Regulation Forum, Burkard Eberlein extols the virtues of the 'open method of coordination' (OMC). While normally securing a certain degree of coordination among diverse national regulatory regimes - by no means a small feat - the OMC may nevertheless lead to occasional deadlocks and breakdowns, and injects a massive dose of 'technical elitism' into a system which, on the contrary, needs to be democratized.

The relative openness and representativeness of policy networks and their actual impact on the policy decisions are the questions at the heart of Christilla Roederer-Rynning's chapter on the McSharry's reform and the 'mad cow disease' crisis in the Common Agricultural Policy. While a number of groups may have access to informal networks, few actually have a real impact on final policy decisions. What seems to matter most, at least in an established policy area like agriculture, are formal decision-making powers and the pressure that some groups - those which have been around longest and can master the greatest expert knowledge, not necessarily the most representative ones - bring to bear on formal institutional actors.

Jeannette Mak offers a new take on Economic and Monetary Union, discussing the way in which policies concerning the euro are in part being made informally. This includes both the substantial efforts made by the European and national actors to implement a coherent and effective information policy with the help of a network dedicated to this task, as well as the running of the Growth and Stability Pact. With respect to the latter, her research shows how national governments bypass informally the formal rules set up to govern decision-making in this important area of EU politics.

Another important dimension of the current phase of European integration is the process of enlargement. In this respect, Sabine Saurugger demonstrates in her contribution how pre-accession policies have generated informal networks composed of Western and Eastern European firms, and how these networks as well as individual firms seek to influence decision-making by the European institutions. Her chapter also shows how different sections within the European Commission are drawn into such networks.

A similar theme is pursued by Mark Rhinard in his chapter on the making of EU policies in the field of biotechnology. His research shows how different interests established themselves in the form of more or less stable networks and how these in turn manage to influence the course of EU policy. Both Saurugger and Rhinard explore in their respective contributions the tension between the formal decision-making structure and the role informal networks seek to play in these areas. In both cases the advantages of operating through informal networks as well as the disadvantages of working through fluid and potentially unstable alliances are made evident.

A final contribution by Daniel Wincott then provides an outlook to the 
future development of this issue. It raises the question as to how the EU will manage informal governance in the future, linking the insights from the empirical studies in the preceding chapters to the discussion of the Commission's White Paper on European Governance. While the formalization of the relationship between policy-makers, interest groups and civil society at large may be on the agenda, for the time being the importance of informal governance is hard to ignore.

\section{CONCLUSION}

The contributions to this volume demonstrate not only that informal governance is an important part of EU politics, but that it deserves more systematic and in-depth analysis than it has attracted in the past. Informal governance is normatively and conceptually more complex than is generally assumed. This volume offers a number of conceptual tools to further our understanding of this phenomenon, and these are applied to a range of key policy-areas of the European Union. These empirical studies show that informal governance is pervasive in EU policy-making, but also that the effects of informal networks are diverse. Informal networks may form easily and frequently in the context of policy-making in the EU, often to overcome the overly rigid and inflexible formal rules and procedures of the European Union. Once in place, informal networks can affect decision-making in significant ways. However, they also suffer from important drawbacks, lacking stability and thereby failing to provide participants with the certainty over future delivery of outcomes which they seek. Informal networks, which appear easily available at a point in time, and nevertheless difficult and costly to maintain, may over time tend to institutionalize themselves in order to entrench their role in the policy process. Ultimately, informal governance causes a dilemma for the legitimacy of European Union. At one level it appears to be a way - the way for some - of delivering reliable policy outcomes against the odds of a cumbersome, super-majoritarian decision-making system. In this perspective, informal governance is the way of making sure that 'Europe works' and delivers results, even if the formal decision rules appear to favour stasis. However, on another level, it constitutes a major threat for the legitimacy of the Union at the time when the way in which decisions are made are increasingly under public scrutiny. And a system relying as heavily on informal governance as does the European Union will not only find it difficult to gain the legitimacy of a wider public expecting democratic accountability from formal institutions. Over-reliance on informal governance ultimately also threatens the efficiency of the system as 'clientelistic' relationships turn into entrenched interests. 
Given the current reform agenda of the European Union, this subject is set to dominate the debate over European integration for some years to come. The European Commission has made a start in dealing with this issue through the proposals in the White Paper. However, it will take a deeper and more sustained effort for the Union as a whole - not just the Commission - to address the quandary of informal governance before it finds a satisfactory solution. In the meantime, this subject will continue to constitute an important part of the research agenda in the study of EU politics.

\section{NOTES}

1. See Christiansen (2000) for a more detailed presentation of this argument.

2. See Richardson (1996) for an overview of the various network approaches and their suitability for the study of EU politics, and Aspinwall and Schneider (2001) for a discussion of different types of institionalist approaches to the EU.

3. An on-line paper by Farrell and Heritier (2002) constitutes a rare excpetion to this lacuna in the literature.

4. See the Report by the Committee of Independent Experts (1999) on this topic, which was commissioned by the European Parliament and constituted the basis of the EP's threat to censure the Commission - a move that was only avoided by the collective resignation of the entire Santer Commission.

5. See Føllesdal (2003) for a discussion of the political theory of the White Paper.

6. See Farrell and Heritier (2002) for the development of a theoretical framework to understand the relationship between formal and informal institutions and an application of this framework to the relationship between EP and Council of Ministers. See Christiansen (2001) for an exploration of the informal links between Commission and Council Secretariat.

7. There are, of course, a number of areas in which the Commission does possess direct implementation powers, most prominently in the field of competition policy. But even in such cases it can be argued that the Commission is required to negotiate with member state authorities in order to achieve its objectives, rather than being able to unilaterally impose its decisions on governments. See the Chapter 7 by Chari and McMahon in this volume for examples of the way in which such negotiations progress informally.

8. For a more thorough discussion of the concept, see Piattoni (2001, pp. 1-18, 193-206). 